\title{
Analysis of Bordetella pertussis clinical isolates circulating in European countries during the period 1998-2012
}

\author{
M. van Gent • C. J. Heuvelman • H. G. van der Heide • H. O. Hallander • A. Advani • \\ N. Guiso • C. H. Wirsing von König • D. F. Vestrheim • T. Dalby • N. K. Fry • D. Pierard • \\ L. Detemmerman • J. Zavadilova - K. Fabianova • C. Logan • A. Habington • M. Byrne • \\ A. Lutyńska • E. Mosiej • C. Pelaz • K. Gröndahl-Yli-Hannuksela • A. M. Barkoff • \\ J. Mertsola • A. Economopoulou • Q. He • F. R. Mooi
}

Received: 8 October 2014 / Accepted: 7 December 2014 / Published online: 20 December 2014

(C) The Author(s) 2014. This article is published with open access at Springerlink.com

\begin{abstract}
Despite more than 50 years of vaccination, pertussis is still an endemic disease, with regular epidemic outbreaks. With the exception of Poland, European countries have replaced whole-cell vaccines (WCVs) by acellular vaccines (ACVs) in the 1990s. Worldwide, antigenic divergence
\end{abstract}

Electronic supplementary material The online version of this article (doi:10.1007/s10096-014-2297-2) contains supplementary material, which is available to authorized users.

M. van Gent $(\varangle) \cdot$ C. J. Heuvelman • H. G. van der Heide •

F. R. Mooi

Centre for Infectious Disease Control (CIb), National Institute for

Public Health and the Environment (RIVM), P.O. Box 1, 3720

BA Bilthoven, The Netherlands

e-mail: marjolein.van.gent@rivm.nl

H. O. Hallander $\cdot$ A. Advani

The Swedish National Institute of Public Health, Solna, Sweden

\section{N. Guiso}

Molecular Prevention and Therapy of Human Diseases, Institut

Pasteur, Paris, France

C. H. Wirsing von König

Labor: Medizin Krefeld MVZ, Helios Klinikum, Krefeld, Germany

D. F. Vestrheim

Department of Bacteriology and Immunology, Norwegian Institute of Public Health, Oslo, Norway

\section{T. Dalby}

Department of Microbiology and Infection Control, Statens Serum Institut, Copenhagen, Denmark

\section{N. K. Fry}

Respiratory and Vaccine Preventable Bacteria Reference Unit, Public Health England-Microbiology References Services, Colindale, United Kingdom in vaccine antigens has been found between vaccine strains and circulating strains. In this work, 466 Bordetella pertussis isolates collected in the period 1998-2012 from 13 European countries were characterised by multi-locus antigen sequence typing (MAST) of the pertussis toxin promoter $(p t x P)$ and of

D. Pierard $\cdot$ L. Detemmerman

National Reference Center for Pertussis, Department of

Microbiology and Infection Control, Universitair Ziekenhuis

Brussel, Brussels, Belgium

\section{J. Zavadilova}

National Reference Laboratory for Pertussis and Diphtheria, National Institute of Public Health, Prague, Czech Republic

\section{K. Fabianova}

Department of Infectious Diseases Epidemiology, National Institute of Public Health, Prague, Czech Republic

C. Logan $\cdot$ A. Habington $\cdot$ M. Byrne

Microbiology Department, Our Lady's Children's Hospital, Dublin, Ireland
A. Lutyńska • E. Mosiej
Department of Sera and Vaccines Evaluation, National Institute of Public Health, National Institute of Hygiene, Warsaw, Poland
C. Pelaz
Centro Nacional de Microbiología, Instituto de Salud Carlos III, Majadahonda, Madrid, Spain
K. Gröndahl-Yli-Hannuksela • A. M. Barkoff · Q. He Department of Infectious Disease Surveillance and Control, National Institute for Health and Welfare, Turku, Finland 
the genes coding for proteins used in the ACVs: pertussis toxin (Ptx), pertactin (Prn), type 2 fimbriae (Fim2) and type 3 fimbriae (Fim3). Isolates were further characterised by fimbrial serotyping, multi-locus variable-number tandem repeat analysis (MLVA) and pulsed-field gel electrophoresis (PFGE). The results showed a very similar B. pertussis population for 12 countries using ACVs, while Poland, which uses a WCV, was quite distinct, suggesting that ACVs and WCVs select for different $B$. pertussis populations. This study forms a baseline for future studies on the effect of vaccination programmes on B. pertussis populations.

\section{Introduction}

Pertussis, or whooping cough, is a highly contagious human infection of the upper respiratory tract caused by the Gramnegative bacterium Bordetella pertussis [1]. Despite the introduction of vaccination against pertussis more than 50 years ago, the disease is still a public health problem worldwide, with epidemic outbreaks occurring every $3-5$ years. In the last 10 years, a resurgence of pertussis was observed in countries with highly vaccinated populations, including Australia [2], Norway [3], Poland [4], the Netherlands [5], the United Kingdom [6] and the United States [7]. One of the hallmarks of the pertussis resurgence is the shift in prevalence from young infants to older persons with waning vaccine-induced immunity $[8,9]$. Several causes have been proposed for the resurgence of pertussis, including improved diagnosis, increased awareness $[10,11]$, decreased vaccine efficacy, waning immunity and pathogen adaptation $[12,13]$. The contribution of these factors to the resurgence of pertussis may differ between countries.

European countries use different vaccines and vaccination schedules for pertussis (Table 1 and http://vaccine-schedule. ecdc.europa.eu/Pages/Scheduler.aspx). Partly due to the side effects of the whole-cell vaccines (WCVs), all European countries, except Poland, have replaced WCVs by acellular vaccines (ACVs) since the 1990s [14]. WCVs are composed of killed $B$. pertussis bacteria, while ACVs consist of 1-5 purified $B$. pertussis proteins: pertussis toxin (Ptx), pertactin (Prn), filamentous haemagglutinin (FHA), type 2 fimbriae (Fim2) and type 3 fimbriae (Fim3). Worldwide, variation in these vaccine antigens have been found between strains used for the production of the vaccines and isolates that are circulating in those countries where these vaccines have been used extensively $[2,15-25]$.

\section{J. Mertsola}

Department of Pediatrics, Turku University Hospital, Turku, Finland

\section{A. Economopoulou}

European Centre for Disease Control and Prevention (ECDC), Stockholm, Sweden
Table 1 Pertussis vaccines currently used in European countries*

\begin{tabular}{ll}
\hline Country & Vaccine \\
\hline Belgium & ACV3 \\
Czech Republic & ACV3 or ACV5 \\
Denmark & ACV1 \\
Finland & ACV2 or ACV3 \\
France & ACV2, ACV3 or ACV5 \\
Germany & ACV2 or ACV3 \\
Ireland & ACV3 \\
Norway & ACV3 \\
Poland & WCV \\
Spain & ACV3 \\
Sweden & ACV2 or ACV3 \\
The Netherlands & ACV3 \\
United Kingdom & ACV3 or ACV5 \\
\hline
\end{tabular}

*Vaccine compositions: ACV1: Ptx; ACV2: Ptx and FHA; ACV3: Ptx, FHA and Prn; ACV5: Ptx, FHA, Prn, Fim2 and Fim3

Besides antigenic variation, recently, $B$. pertussis isolates have emerged which produce higher levels of a number of virulence factors in vitro, including Ptx $[5,26]$. These isolates carry a new allele for the Ptx promoter, ptxP3, and have replaced the resident $p t x P 1$ isolates in many countries. The emergence of $p t x P 3$ isolates is associated with the increase in pertussis notifications in the Netherlands since 1996 [5]. Nowadays, $p t x P 3$ isolates are found worldwide [20-22, 25, 27-30]. Moreover, recently, B. pertussis isolates have been observed that do not express one or more vaccine components, in particular, Prn [7, 31-39].

Monitoring changes in the European B. pertussis populations and studying the impact of these changes on the disease burden are important in order to establish the most effective pertussis vaccines and vaccination strategies. To study these changes, a European network, designated EUpertstrain, was created in 2001, with the main aim of collecting and typing of European B. pertussis isolates. The number of participating countries increased from five in 2001 to nine in 2013 [40-43]. Members of the EUpertstrain group collected and typed isolates on a regular basis between 2001 and 2013. Typing involved multi-locus antigen sequence typing (MAST), fimbrial serotyping, multi-locus variable-number tandem repeat analysis (MLVA) and pulsed-field gel electrophoresis (PFGE). However, direct comparison of these isolates collected during the study period was only performed by PFGE analyses [41-43].

This present study is part of a European Centre for Disease Control and Prevention (ECDC)-funded network, EUpertlabnet, which focuses on the laboratory surveillance of whooping cough in EU Member States and European Economic Area (EEA) countries. In this study, we present the typing results of isolates collected from 13 countries 
(Belgium, the Czech Republic, Denmark, Finland, France, Germany, Ireland, Norway, Poland, Spain, Sweden, the Netherlands and the United Kingdom) between 2000 and 2012. Further, the typing of previous collections was extended and the results were combined to give an overview of $B$. pertussis isolates circulating in European countries between 1998 and 2012.

\section{Materials and methods}

\section{B. pertussis isolates}

B. pertussis isolates were grown on Bordet-Gengou (BG) agar with $15 \%$ sheep blood and incubated for 3 to 4 days at $35^{\circ} \mathrm{C}$. In total, $466 \mathrm{~B}$. pertussis isolates were included in this study (Supplementary Table S1). Isolates collected between 1998 and 2009 were previously analysed by PFGE [41-43]. Here, we extended these analyses by typing more isolates from this period. Further, we present novel data from five EU countries; Belgium ( $n=20$, isolated in 2000-2012), the Czech Republic ( $n=20$, isolated in 2008-2012), Ireland $(n=$ 20 , isolated in 2003-2012), Poland ( $n=20$, isolated in 2000 2012) and Spain ( $n=12$, isolated in 2004-2012).

\section{Multi-locus antigen sequence typing (MAST)}

Polymorphisms in the genes for proteins used in the ACVs (PtxA, Prn, Fim2 and Fim3) were analysed as described previously $[5,15,44,45]$. The pertussis toxin promoter, $p t x P$, was also included, as previous studies have shown that the ptxP3 allele is an important characteristic of successful isolates [5, 20-22, 25, 27-30]. For DNA isolation, bacterial cells were lysed in Tris-EDTA buffer (Sigma-Aldrich, Zwijndrecht, the Netherlands, $1.0 \mathrm{M}$ Tris- $\mathrm{HCl}$, containing 0.1 M EDTA, $100 \times$ concentrated) at $95^{\circ} \mathrm{C}$ for $5 \mathrm{~min}$, centrifuged briefly and used in a polymerase chain reaction (PCR) assay.

\section{Serotyping}

A bacterial suspension was mixed on a glass slide with monoclonal or polyclonal antibodies against Fim 2 or Fim3 (National Institute for Biological Standards and Control (NIBSC), South Mimms, UK). Agglutination was determined after a maximum of $30 \mathrm{~s}$ to avoid false-positive agglutination [44]. Bacterial suspensions were mixed with a physiological salt solution to determine auto-agglutination.

Multi-locus variable-number tandem repeat analysis (MLVA)

For MLVA, the variable number of tandem repeats in six loci (VNTR1, VNTR3a, VNTR3b, VNTR4, VNTR5 and VNTR6) was determined as described previously [23, 46].
Pulsed-field gel electrophoresis (PFGE)

All EUpertstrain isolates were previously analysed by PFGE at the Swedish Institute for Communicable Disease Control (SMI) [43]. PFGE of isolates from Belgium, Ireland and Poland was performed by the respective countries, whereas PFGE of isolates from the Czech Republic and Spain was performed at the Finnish National Institute for Health and Welfare (THL). Gel images of all isolates from the five countries were also analysed at the Finnish THL. The PFGE protocol, reference strains used and profile analysis were the same as those previously described [43]. The profiles were analysed by using BioNumerics software version 4.61 (Applied Maths, Sint-Martens-Latem, Belgium). The Swedish nomenclature was used and based on cluster analysis with the group method with $1 \%$ band tolerance and $1 \%$ optimisation settings. The resulting profiles were designated BpSR1, BpSR2, BpSR3 etc. for those isolates with profiles first detected in Sweden. Isolates first identified in a country other than Sweden, such as Finland, were designated BpFINR1, BpFINR2 etc.

\section{Results}

The EUpertstrain and EUpert-labnet collections

One of the aims of the EUpertstrain network is to collect isolates from different European countries in order to assess the emergence and spread of new variants of $B$. pertussis. A secondary aim is to determine the effect, if any, of different vaccination strategies on the pertussis burden and the emergence of new variants. Analyses of the three EUpertstrain collections isolated between 1998 and 2009 by PFGE and analysis of the EUpert I collection isolated between 1998 and 2001 by MLVA have already been published [40-43].

Here, we extend this work to the EUpert-labnet collection by including five more EU countries: Belgium, the Czech Republic, Ireland, Poland and Spain (Table 2). Further, additional typing was performed on previously collected isolates. The old and new data were integrated to give an overview of (country-specific) changes of the B. pertussis populations in the participating European countries. Isolates collected between 1998 and 2012 were aggregated in three periods to obtain a comparable number of isolates per year; 1998-2001 ( $n=106), 2002-2006(n=165)$ and 2007-2012 $(n=195)$. As PCR is replacing culture for pertussis diagnosis, obtaining sufficient strains for population studies has become difficult. The number of participating countries for the three periods was 7, 11 and 12, respectively (Table 2). For Finland, France, the Netherlands and Sweden, 17 to 23 isolates were available for each period. In contrast, for Norway and the Czech 
Table 2 Number of Bordetella pertussis clinical isolates used in this study

\begin{tabular}{lrrrr}
\hline Country & $1998-2001$ & $2002-2006$ & $2007-2012$ & Total \\
\hline Belgium & 2 & 8 & 10 & 20 \\
Czech Republic & 0 & 0 & 20 & 20 \\
Denmark & 0 & 20 & 23 & 43 \\
Finland & 20 & 20 & 17 & 57 \\
France & 20 & 20 & 20 & 60 \\
Germany & 17 & 18 & 0 & 35 \\
Ireland & 0 & 5 & 15 & 20 \\
Norway & 0 & 0 & 20 & 20 \\
Poland & 11 & 7 & 2 & 20 \\
Spain & 0 & 2 & 10 & 12 \\
Sweden & 17 & 20 & 20 & 57 \\
The Netherlands & 19 & 23 & 20 & 62 \\
United Kingdom & 0 & 22 & 18 & 40 \\
Total & 106 & 165 & 195 & 466 \\
\hline
\end{tabular}

Republic, isolates were only available for period 2007-2012. Table 1 shows the pertussis vaccines currently used in European countries.

\section{Changes in allele frequencies}

We investigated changes in frequencies of the alleles for four proteins used in ACVs: ptxA, prn, fim 2 and fim3. The pertussis toxin promoter, $p t x P$, was also included, as several previous studies have shown that the ptxP3 allele is an important characteristic of recent clinical isolates [5, 20, 28]. Isolates were also serotyped to assess expression of the fim 2 and fim 3 genes. All allelic variants discussed here are associated with changes in protein structure. An overview of allelic and protein variants is provided in previously published reviews [12, 47].

For our analysis, we included data only if at least five isolates were available in a particular period. In general, Poland was found to be distinct, while the remaining 12 countries showed minor differences in their $B$. pertussis populations. Therefore, except for the $p t x A$ alleles and serotypes, we limited the comparisons to Poland and pooled the remaining 12 countries. All data are represented in Supplementary Table S1.

\section{ptxA alleles}

The ACVs currently used in the European countries contain $p t x A 2$ and ptxA4 [12] and the Polish WCV contains only ptxA2 [48]. Essentially, no differences were found between the 13 countries with respect to $p t x A$ alleles. The non-vaccine type allele ptxA1 was identified in 428 out of the 429 isolates analysed. One isolate, isolated in Sweden in 1998, harboured the $p t x A 2$ allele.

\section{prn alleles}

The ACVs currently used in the European countries contain prn1 and prn7 [12] and the Polish WCV contains only prn1 [48]. In the group of 12 countries, four prn alleles were observed in this study, prn1, prn2, prn3 and prn13. The prn 13 allele was detected once in Sweden during the period 1998-2001. The prn3 allele was found in all three periods but decreased in frequency from $10 \%$ in 1998-2001 to $4 \%$ in 2002-2006 and to $1 \%$ in 2007-2012. The two minor prn alleles prn13 and prn3 were combined into one group in Fig. 1a. In the 12 countries, prn 2 predominated in 1998 2001 with a frequency of $84 \%$, increasing to $91 \%$ in 2002 2006 and to $99 \%$ 2007-2012 (Fig. 1a). In Poland, the frequencies of prn1 in the periods 1998-2001 and 2002-2006 were, respectively, 55 and 43 \% (Fig. 1b). Two Polish isolates were available in 2007-2012, both containing prn1.

ptxP alleles

Three $p t x P$ alleles were found in this study, $p t x P 1, p t x P 3$ and ptxP20. ptxP20 was found once in the Czech Republic in 2007-2012 and not included in Fig. 2. An increasing prevalence of ptxP3 isolates was observed in the group of 12 countries from $57 \%$ in 1998-2001 to $87 \%$ in 2002-2006 and to $97 \%$ in 2007-2012 (Fig. 2a). In Poland, a distinct trend was found. ptxPl predominated in both periods 1998-2001 and 2002-2006, with frequencies of 82 and $100 \%$, respectively (Fig. 2b). Only two Polish isolates were available in 2007-2012, both containing $p t x P 1$.

\section{fim2 alleles}

Two fim 2 alleles have been found worldwide, fim 2-1 and fim 2-2 [47]. Only fim 2-1 is present in the currently used ACVs [12] and the Polish WCV [48]. In this collection, fim2-2 isolates were only detected in Poland and Belgium, while the remaining isolates harboured the fim 2-1 allele. In Belgium, one fim 2-2 isolate was observed in the period 2002-2006. In Poland, the fim2-2 frequencies were $55 \%$ in 1998-2001 and $43 \%$ in 2002-2006 (Fig. 3). Only two Polish isolates were available for the period 2007-2012: one isolate harboured the fim 2-1 allele and one harboured the fim 2-2 allele; therefore, the prevalences for the period 2007-2012 were not included in the figure.

\section{fim3 alleles}

Five fim 3 alleles were found in this study, fim 3-1 (found in ACVs [12]) and the Polish WCV [48]), fim3-2, fim3-3, fim 3-4 


\section{A}

\section{prn alleles 12 pooled countries}

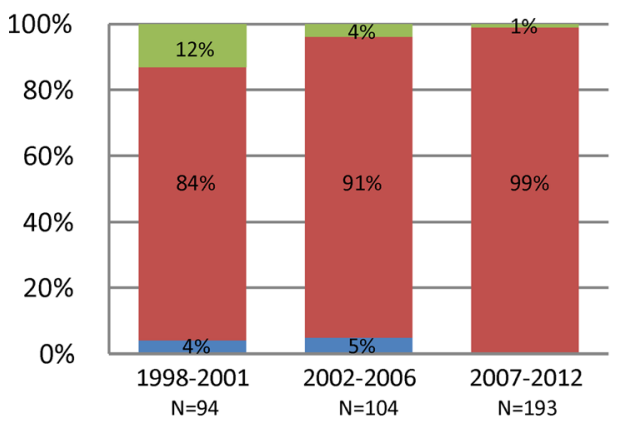

B

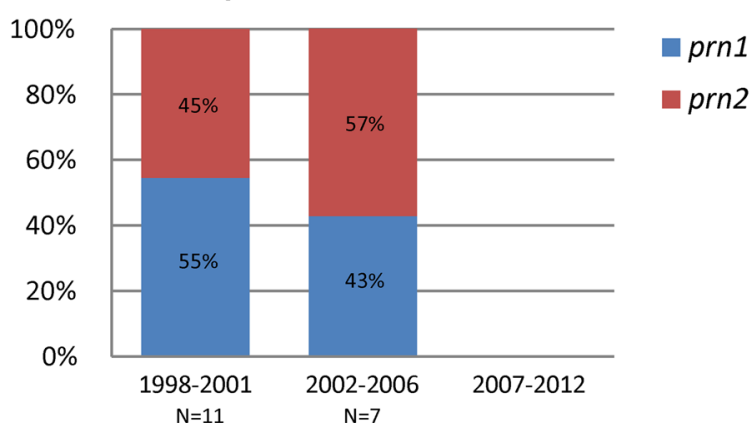

Fig. 1 Frequencies of the prn alleles in the period 1998-2012. Isolates were aggregated in three periods, 1998-2001, 2002-2006 and 20072012. a Allele frequencies in the 12 pooled countries: Belgium, the Czech Republic, Denmark, Finland, France, Germany, Ireland, Norway, Spain, Sweden, the Netherlands and the United Kingdom. b Allele frequencies in Poland. Due to the limited availability of Polish isolates in the period 2007-2012 $(n=2)$, no data are included for this period. The percentages and number of strains analysed in the different periods are indicated

and fim 3-6. Two fim 3-3 isolates were found, one in the Netherlands (in the period 2007-2012) and one in Denmark (in the period 2007-2012). A fim 3-4 isolate was found in France (in the period 2007-2012) and a fim3-6 isolate was found in Belgium (in the period 2007-2012). The three minor fim 3 alleles, fim 3-3, fim 3-4 and fim 3-6, were combined into one group in Fig. 4a. In the group of 12 countries, fim 3-1 was found with frequencies of 50,41 and $56 \%$ in the periods 1998-2001, 2002-2006 and 2007-2012, respectively (Fig. 4). In Poland, fim3-1 predominated in the period 1998-2001 (frequency $82 \%$ ) and increased in frequency to $100 \%$ in the period 2002-2006 (Fig. 4b). Only two Polish isolates were available for the period 2007-2012, both containing fim 3-1.

Fimbrial serotyping

B. pertussis produces two serologically distinct fimbriae, designated serotype 2 (Fim2) and serotype 3 fimbriae (Fim3). A $B$. pertussis isolate may produce a single serotype or both serotypes. Therefore, three combinations are possible: Fim2, Fim3 and Fim2,3. Ireland and Poland were distinct with

\section{A ptxP alleles 12 pooled countries}

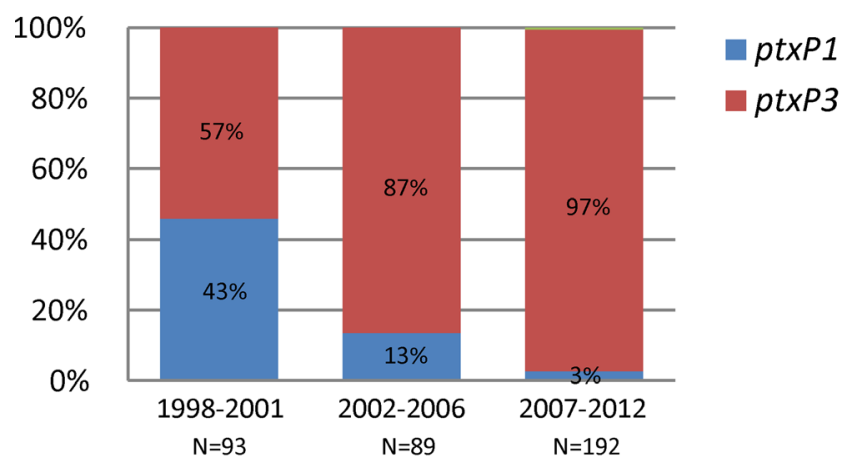

B

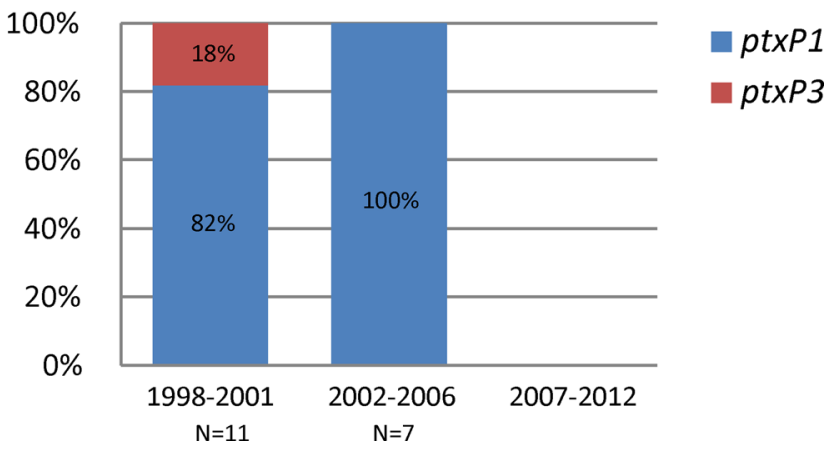

Fig. 2 Frequencies of the $p t x P$ alleles in the period 1998-2012. See caption of Fig. 1 for further details

respect to fimbrial serotypes, whereas minor differences were found between the remaining 11 countries. Therefore, Ireland and Poland were treated separately, while the data of the remaining 11 countries were pooled. Fim 3 predominated in the group of 11 countries with frequencies of $69 \%$ in 1998 $2001,93 \%$ in 2002-2006 and $86 \%$ in 2007-2012 (Fig. 5a). In Ireland, lower frequencies of Fim3 were found: $60 \%$ in

\section{fim2 alleles Poland}

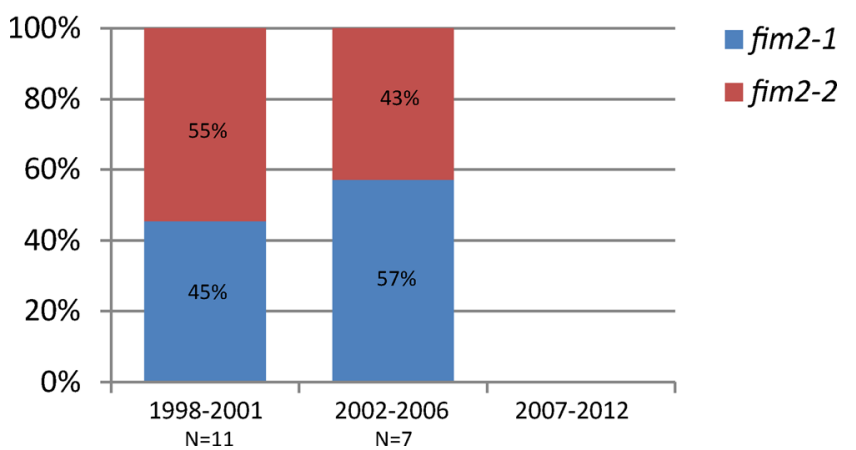

Fig. 3 Frequencies of the fim 2 alleles in the period 1998-2006 in Poland. Two periods are indicated, 1998-2001 and 2002-2006. Due to the limited availability of Polish isolates in 2007-2012 $(n=2)$, no data are included for this period. In the remaining 12 countries, only fim $2-1$ was observed, with the exception of Belgium, where one fim 2-2 isolate was identified 


\section{A}

fim3 alleles 12 pooled countries

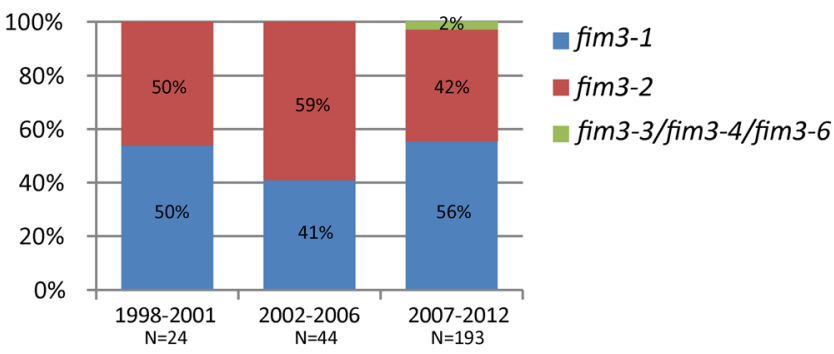

\section{B fim 3 alleles Poland}

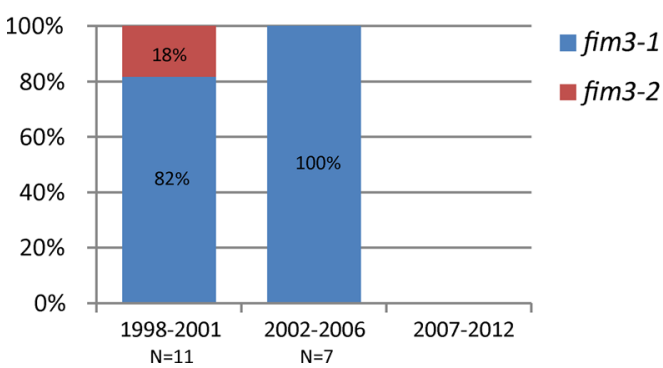

Fig. 4 Frequencies of the fim 3 alleles in the period 1998-2012. See caption of Fig. 1 for further details

2002-2006 and $40 \%$ in 2007-2012. No Irish isolates were available for the period 1998-2001 (Fig. 5b). In Poland, Fim2 predominated in 1998-2001 and 2006-2006 (frequencies of 73 and $100 \%$, respectively) (Fig. 5c). Only two Polish isolates were available in 2007-2012, both of which were Fim2. The Polish WCV is derived from strains which produce both Fim2 and Fim3 [49]. One strain, isolated in Spain in 2010, was found to be auto-agglutinable (data not shown).

Multi-locus variable-number tandem repeat analysis (MLVA)

Thirty-four MLVA types (MTs) were found in the 13 countries. MTs that were found less than five times in the group of 12 countries or in Poland were combined and designated as group R in Fig. 6a, b. MT27 predominated in the group of 12 countries (frequencies from 54 to $100 \%$ per country) but was found once in Poland (in 1994-2001). MT27 predominated in 1998-2001, with a frequency of $49 \%$, which increased to $86 \%$ in 2002-2006 and decreased to $74 \%$ in 2007-2012 (Fig. 6a). MT29 predominated only in 1998-2001, with a frequency of $22 \%$, which decreased to $0 \%$ in 2002-2006 and increased slightly to $1 \%$ in 2007-2012. MT78 predominated in Finland in 2007-2012 (data not shown) (frequency $53 \%$ ). MT78 was found once in Norway (in the period 2007 2012) and once in Germany (in the period 1998-2001). In Poland, MT70 predominated, with frequencies of $55 \%$ in 1998-2001 and 14\% in 2002-2006 (Fig. 6b). Besides Poland, MT70 has been found once in Belgium in the period 20022006. During the period 2002-2006, MT29 predominated in Poland, with a frequency of $57 \%$.

\section{A serotypes 11 pooled countries}

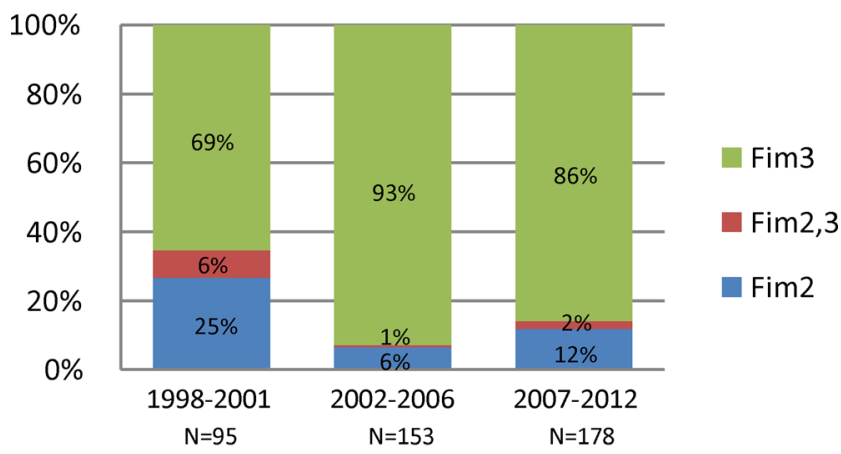

B serotypes Ireland

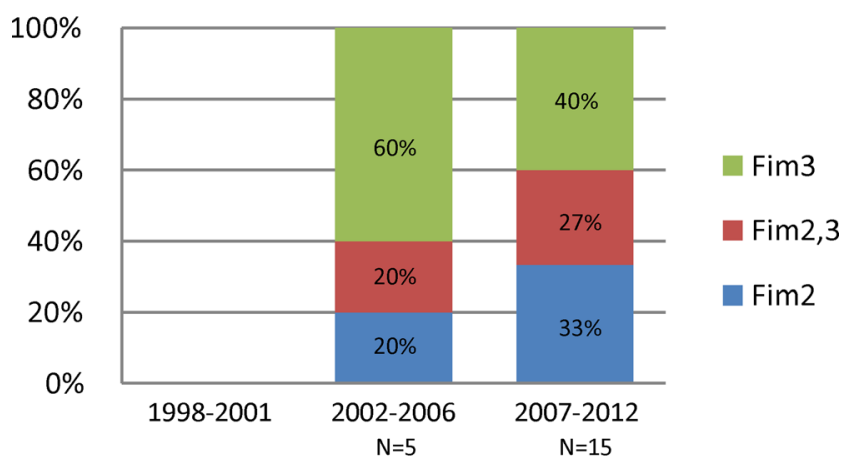

C serotypes Poland

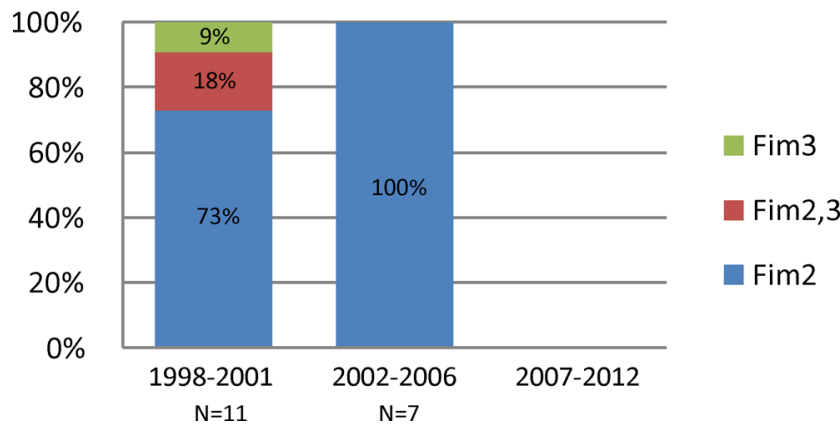

Fig. 5 Frequencies of the serotypes in the period 1998-2012. a Serotype frequencies of the 11 pooled countries; Belgium, the Czech Republic, Denmark, Finland, France, Germany, Norway, Spain, Sweden, the Netherlands and the United Kingdom. b Serotype frequencies in Ireland. c Serotype frequencies in Poland. See caption of Fig. 1 for details

Pulsed-field gel electrophoresis (PFGE)

Eighty-seven PFGE types were found in the 13 countries. PFGE types that were found less than five times in the group of 12 countries were combined and designated as group $\mathrm{R}$ in Fig. 7a. In the group of 12 countries, increasing frequencies were observed for BpSR3 (0 \% in 1998-2001 to $23 \%$ in 2007-2012) and BpSR10 (10\% in 1998-2001 to $19 \%$ in 2007-2012). Decreasing trends have been found for BpSR11 ( $29 \%$ in $1998-2001$ to $13 \%$ in 2007-2012). No differences 


\section{A}

Predominating MLVA types 12 pooled countries

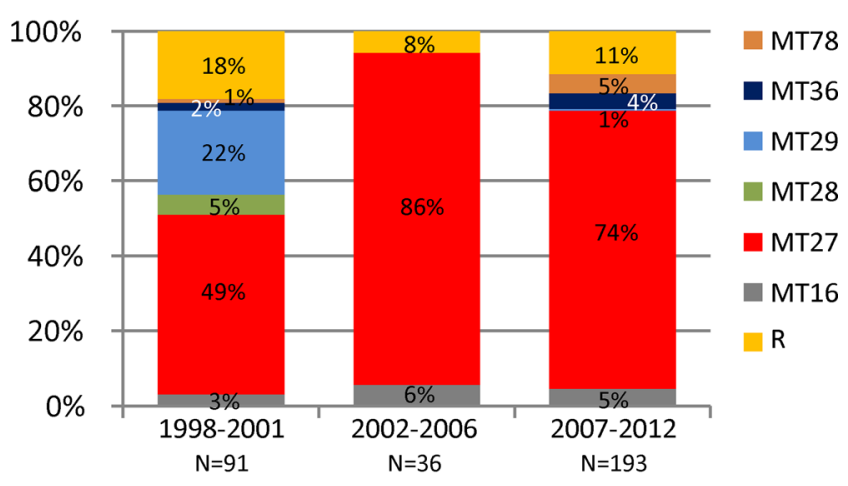

B
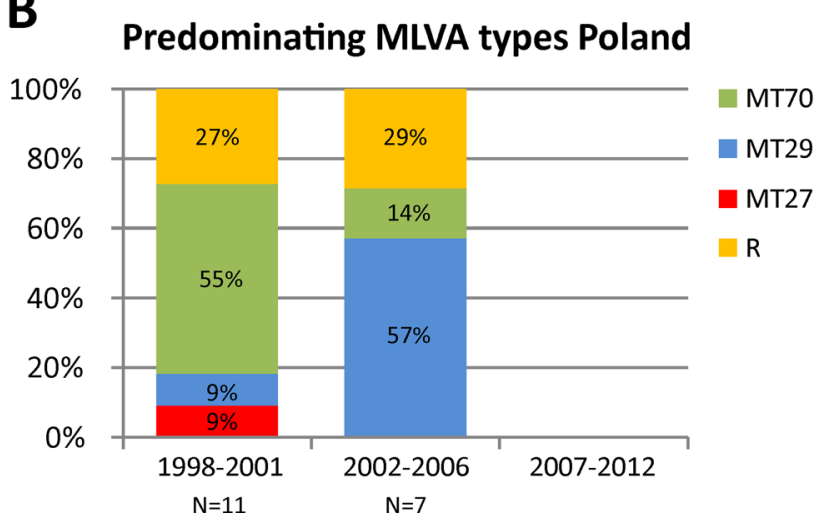

Fig. 6 Frequencies of the predominating multi-locus variable-number tandem repeat analysis (MLVA) types in the period 1998-2012. See caption of Fig. 1 for further details

were found for the frequencies of BpSR5 (7 \% in 1998-2001, $9 \%$ in 2002-2006 and $11 \%$ in 2007-2012) and BpSR 12 (4\% in $1998-2001,8 \%$ in $2002-2006$ and $5 \%$ in 2007-2012) (Fig. 7a). In Poland, BpSR23 predominated in the period 1998-2001 (frequency $46 \%$ ). The predominating PFGE type in Europe, BpSR11, was found once in Poland, in the period 1998-2001 (Fig. 7b).

\section{Discussion}

In this study, we analysed B. pertussis isolates from 13 European countries during the period 1998-2012. In general, our comparison showed that 12 countries had very similar B. pertussis populations (Belgium, the Czech Republic, Denmark, Finland, France, Germany, Ireland, the Netherlands, Norway, Spain, Sweden and the United Kingdom), while Poland was quite distinct. As noted previously, in all countries, circulating isolates were distinct from vaccine strains with respect to one or more of the investigated antigens [2, 15-25].

The $p t x A$ gene was found to be highly monomorphic and, with one exception, all circulating isolates carried the non-
A

Predominating PFGE types 12 pooled countries

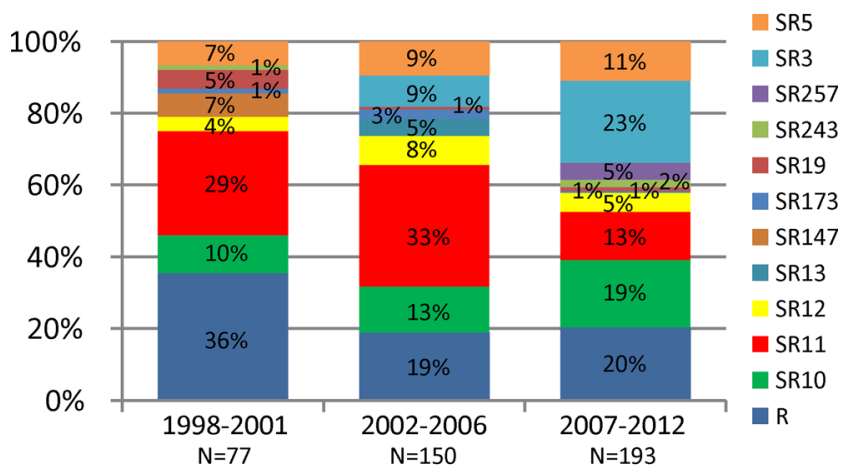

B

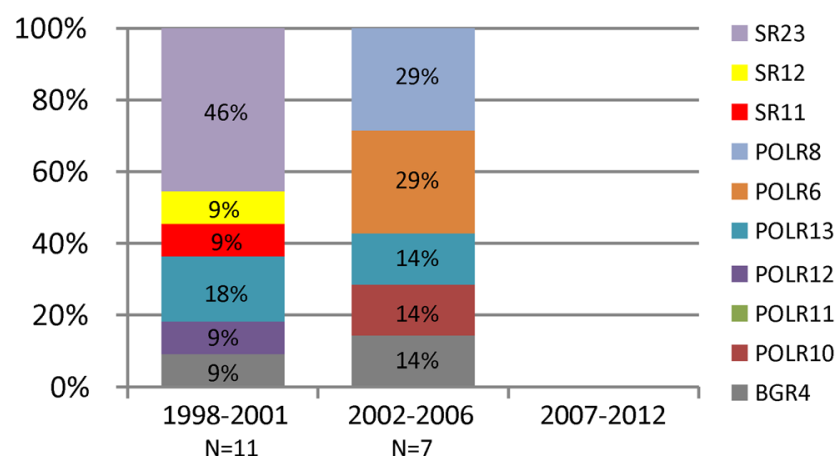

Fig. 7 Frequencies of the predominating pulsed-field gel electrophoresis (PFGE) types in the period 1998-2012. See caption of Fig. 1 for further details

vaccine type allele $p t x A 1$. Three $p t x P$ alleles were observed in this collection of isolates, $p t x P 1, p t x P 3$ and $p t x P 20$. A notable observation was the low percentage of $p t x P 3$ isolates in Poland $(10 \%, n=20)$ compared to the other countries (average $72 \%$, range $37-100 \%$ ). Interestingly, the two Polish ptxP3 isolates were found in the first period, 1998-2001, but not in the later periods. Possibly, $p t x P 3$ isolates do not have a fitness advantage in Poland, in contrast to the other 12 countries. Further, although the non-vaccine type allele prn 2 was found at frequencies of 45 and $57 \%$ in the periods 1998-2001 and 2002-2006 in Poland, respectively, these percentages were lower than those observed in the remaining 12 countries (average $83 \%$, range $37-100 \%$ ). Comparing the clinical outcome between $p t x P 1$ - and ptxP3-infected individuals, especially in Poland, would be useful.

In Poland, two fim 2 alleles circulated in approximately equal frequencies, fim 2-1 (the vaccine type in Poland) and fim 2-2. In contrast, in the remaining countries, only fim 2-1 was observed, with the exception of Belgium, where a single fim 2-2 isolate was identified. The Belgian fim 2-2 isolate was linked to the same MLVA and PFGE type (MT70 and BpBGR4, respectively) as $30 \%$ of the Polish fim 2-2 isolates, suggesting that the fim 2-2 isolate was introduced in Belgium from Poland. The fim 2-2 allele was also observed in the pre- 
vaccination era in the Netherlands $(57 \%, n=7)$, while all isolates from 1965 or later harboured fim2-1 [45]. More recently, fim 2-2 isolates were observed in Moscow ( $89 \%$ in the period 1990-2004) and Australia (36 \% in the period 19982008) $[50,51]$. In both Poland and Australia, a significant percentage of the fim 2-2 isolates were linked to MT70 (80 and $88 \%$, respectively), possibly suggesting a common origin. However, independent genesis and fixation of the fim 2-2 single nucleotide polymorphism (SNP) by different B. pertussis lineages may also be possible. The latter would suggest that the mutation has a significant effect on fitness.

The limited distribution of fim 2-2 isolates in Europe compared to Moscow and Poland could be due to geographic isolation, as travelling to Poland and/or Moscow from Western Europe was restricted until the late 1980s. However, in the Czech Republic, which was also located in the former Eastern Europe, no fim 2-2 isolates have been observed. Another cause for the observation that the distribution of fim2-2 isolates was limited to Poland and Russia could be the use of the pertussis vaccines, as in Poland and Moscow, a WCV is still used, while an ACV has already been introduced in the Czech Republic in 2007.

The Polish and Irish populations showed higher Fim2 frequencies compared to the other 11 countries (80 and $30 \%$, respectively). An association between Fim2 and the prevalence of fim 2-2 isolates has been found previously in the United Kingdom, where isolates collected between 1920 and 2002 were studied [52]. All isolates with the fim $2-2$ allele $(n=$ 20) were Fim 2 . This was also observed in Poland, where $90 \%$ of the fim 2-2 isolates were Fim2. However, no fim 2-2 alleles have been found in Ireland in this study.

MT27 is the predominating MT in Europe. Previous European studies showed a linkage between $p t x P 3$ and MT27 [17, $18,46]$. Indeed, $97 \%$ of MT27 isolates in this study harboured the $p t x P 3$ allele. MT27 was also the predominating MT in countries outside Europe, including Australia [2], Japan [25] and the United States [22]. One of the two Polish ptxP3 isolates was also typed as MT27.

The Fim and Prn types of Danish isolates were similar to the isolates found in other countries, except Poland. Since the Danish vaccine contains only Ptx, the changes to the Fim and Prn types in Danish isolates may be the result of overflow from neighbouring countries, rather than selective pressure from the Ptx vaccine.

Five predominant PFGE types have been found in Europe, BpSR3, BpSR5, BpSR10, BpSR11 and BpSR12 [43]. These PFGE types were also predominant in at least one Canadian province, where 317 out of 434 (73\%) isolates collected between 1998 and 2006 belonged to the PFGE types BpSR5, BpSR11 and BpSR12 [24]. However, no isolate with PFGE types BpSR3 and BpSR10 have been found in Canada so far, suggesting some geographic differences in isolates.

The present study showed minor differences in European countries which used ACVs based on MAST, fimbrial serotyping, MLVA and PFGE. However, Poland, the only country included in this study where a WCV is still used, showed a distinct population.

A distinct population compared to Europe has also been found in Serbia, where a WCV has been continued to be used since 1957 [53]. Both countries, Poland and Serbia, have a vaccination history including several changes of strain compositions since the 1960s, which could explain the distinct $B$. pertussis populations compared to the European countries where an ACV is used. The Polish and Serbian B. pertussis populations both show high prn1 frequencies, $43 \%$ in $2002-$ 2006 and $47 \%$ in 1985-2000, respectively [43], compared to high prn2 frequencies ( $>90 \%$ ) in European countries, where ACVs have been used for many years.

The immune response induced by the two vaccines is different. WCVs induce a broad immune response, but with relatively low titres, whereas $\mathrm{ACV}$ s induce high titres against only a few antigens. Theoretical studies suggest that a change from a broad to a narrow immune response will favour the emergence of escape variants [54]. Indeed, several studies have shown the emergence of Prn-deficient strains in populations where ACVs are used [7, 31-39]. This is in contrast with Poland and Serbia, where a WCV has been used for many years. No Prn-deficient strains have been detected in both countries $[48,53]$.

This study has some limitations. Isolates were not sampled randomly and the sample size from some countries was small. However, as culture is being replaced by PCR, less and less isolates are available for typing and most members of this study sent all isolates available. Further, it was not possible to establish relationships between strain type and vaccination status, as very limited vaccination data were available. Further, FHA, also a component in some ACVs, was not included, as the large size of the gene precluded analyses. Interestingly, FHA-deficient isolates have been described [32]. In the future, targeted sequencing of genes for vaccine antigens may be replaced by whole genome sequencing, which may reveal other relevant loci to be included in MAST [51, 55]. This study was not set up to identify isolates not producing Prn in Europe, as a recent study has already addressed this issue [38]. Overall, low prevalences $(<4 \%)$ of Prn-deficient strains were found, except in Norway and France (25\% in 2007-2009 and $15 \%$ in 2013, respectively [56]).

Acknowledgements This present study is part of an ECDC-funded network EUpert-labnet with a focus on the laboratory surveillance of whooping cough in Member States/EEA countries (ECDC/2011/013). The EUpertstrain I project was supported by the European Commission Quality of Life Program (QLK2-CT-2001-01819), and the EUpertstrain II and III studies were supported by GlaxoSmithKline (Rixensart, Belgium) and Sanofi Pasteur MSD (Lyon, France). The processing of Czech isolates and the provision of data were supported by research grant NT/ 14058-3 of the Internal Grant Agency of the Ministry of Health of the Czech Republic. The processing of Belgian isolates and the provision of data were performed in the frame of the Belgian National Reference 
Centre for pertussis supported by the Belgian Ministry of Social Affairs through a fund within the Health Insurance System.

Conflict of interest The authors declare that they have no conflict of interest.

Open Access This article is distributed under the terms of the Creative Commons Attribution License which permits any use, distribution, and reproduction in any medium, provided the original author(s) and the source are credited.

\section{References}

1. de Gouw D, Diavatopoulos DA, Bootsma HJ, Hermans PW, Mooi FR (2011) Pertussis: a matter of immune modulation. FEMS Microbiol Rev 35:441-474

2. Octavia S, Sintchenko V, Gilbert GL, Lawrence A, Keil AD, Hogg G, Lan R (2012) Newly emerging clones of Bordetella pertussis carrying prn2 and ptxP3 alleles implicated in Australian pertussis epidemic in 2008-2010. J Infect Dis 205:1220-1224

3. Dudman SG, Trøseid M, Jonassen TØ, Steinbakk M (2006) Whooping cough - an increasing problem in Norway. Tidsskr Nor Laegeforen 126:305-308

4. Stefanoff P, Paradowska-Stankiewicz IA, Lipke M, Karasek E, Rastawicki W, Zasada A, Samuels S, Czajka H, Pebody RG (2014) Incidence of pertussis in patients of general practitioners in Poland. Epidemiol Infect 142:714-723

5. Mooi FR, van Loo IH, van Gent M, He Q, Bart MJ, Heuvelman KJ, de Greeff SC, Diavatopoulos D, Teunis P, Nagelkerke N, Mertsola J (2009) Bordetella pertussis strains with increased toxin production associated with pertussis resurgence. Emerg Infect Dis 15:12061213

6. Amirthalingam G, Gupta S, Campbell H (2013) Pertussis immunisation and control in England and Wales, 1957 to 2012: a historical review. Euro Surveill 18(38). pii: 20587

7. Queenan AM, Cassiday PK, Evangelista A (2013)Pertactin-negative variants of Bordetella pertussis in the United States. N Engl J Med 368:583-584

8. Halperin SA (2007) The control of pertussis -2007 and beyond. N Engl J Med 356:110-113

9. van der Maas NA, Mooi FR, de Greeff SC, Berbers GA, Spaendonck MA, de Melker HE (2013) Pertussis in the Netherlands, is the current vaccination strategy sufficient to reduce disease burden in young infants? Vaccine 31:4541-4547

10. Cherry JD (2005) The epidemiology of pertussis: a comparison of the epidemiology of the disease pertussis with the epidemiology of Bordetella pertussis infection. Pediatrics 115:1422-1427

11. Zepp F, Heininger U, Mertsola J, Bernatowska E, Guiso N, Roord J, Tozzi AE, Van Damme P (2011) Rationale for pertussis booster vaccination throughout life in Europe. Lancet Infect Dis 11:557-570

12. Mooi FR, van der Maas NA, de Melker HE (2014) Pertussis resurgence: waning immunity and pathogen adaptation - two sides of the same coin. Epidemiol Infect 142:685-694

13. Hegerle N, Guiso N (2013) Epidemiology of whooping cough \& typing of Bordetella pertussis. Future Microbiol 8:1391-1403

14. Berbers GA, de Greeff SC, Mooi FR (2009) Improving pertussis vaccination. Hum Vaccin 5:497-503

15. Mooi FR, van Oirschot H, Heuvelman K, van der Heide HG, Gaastra W, Willems RJ (1998) Polymorphism in the Bordetella pertussis virulence factors P.69/pertactin and pertussis toxin in The
Netherlands: temporal trends and evidence for vaccine-driven evolution. Infect Immun 66:670-675

16. Caro V, Bouchez V, Guiso N, Gatti B, Agosti MR, Ayala SE (2007) Pertussis in Argentina and France. Vaccine 25:4335-4339

17. Litt DJ, Neal SE, Fry NK (2009) Changes in genetic diversity of the Bordetella pertussis population in the United Kingdom between 1920 and 2006 reflect vaccination coverage and emergence of a single dominant clonal type. J Clin Microbiol 47:680-688

18. Advani A, Van der Heide HG, Hallander HO, Mooi FR (2009) Analysis of Swedish Bordetella pertussis isolates with three typing methods: characterization of an epidemic lineage. J Microbiol Methods 78:297-301

19. Mosiej E, Augustynowicz E, Zawadka M, Dabrowski W, Lutyńska A (2011) Strain variation among Bordetella pertussis isolates circulating in Poland after 50 years of whole-cell pertussis vaccine use. J Clin Microbiol 49:1452-1457

20. Kallonen T, Gröndahl-Yli-Hannuksela K, Elomaa A, Lutyńska A, Fry NK, Mertsola J, He Q (2011) Differences in the genomic content of Bordetella pertussis isolates before and after introduction of pertussis vaccines in four European countries. Infect Genet Evol 11: 2034-2042

21. Petersen RF, Dalby T, Dragsted DM, Mooi F, Lambertsen L (2012) Temporal trends in Bordetella pertussis populations, Denmark, 19492010. Emerg Infect Dis 18:767-774

22. Schmidtke AJ, Boney KO, Martin SW, Skoff TH, Tondella ML, Tatti KM (2012) Population diversity among Bordetella pertussis isolates, United States, 1935-2009. Emerg Infect Dis 18:1248-1255

23. van Gent M, Bart MJ, van der Heide HG, Heuvelman KJ, Mooi FR (2012) Small mutations in Bordetella pertussis are associated with selective sweeps. PLoS One 7:e46407

24. Shuel M, Jamieson FB, Tang P, Brown S, Farrell D, Martin I, Stoltz J, Tsang RS (2013) Genetic analysis of Bordetella pertussis in Ontario, Canada reveals one predominant clone. Int J Infect Dis 17:e413-e417

25. Miyaji Y, Otsuka N, Toyoizumi-Ajisaka H, Shibayama K, Kamachi $\mathrm{K}$ (2013) Genetic analysis of Bordetella pertussis isolates from the 2008-2010 pertussis epidemic in Japan. PLoS One 8:e77165

26. de Gouw D, Hermans PW, Bootsma HJ, Zomer A, Heuvelman K, Diavatopoulos DA, Mooi FR (2014) Differentially expressed genes in bordetella pertussis strains belonging to a lineage which recently spread globally. PLoS One 9:e84523

27. Bart MJ, Harris SR, Advani A, Arakawa Y, Bottero D, Bouchez V, Cassiday PK, Chiang CS, Dalby T, Fry NK, Gaillard ME, van Gent M, Guiso N, Hallander HO, Harvill ET, He Q, van der Heide HG, Heuvelman K, Hozbor DF, Kamachi K, Karataev GI, Lan R, Lutyłska A, Maharjan RP, Mertsola J, Miyamura T, Octavia S, Preston A, Quail MA, Sintchenko V, Stefanelli P, Tondella ML, Tsang RS, Xu Y, Yao SM, Zhang S, Parkhill J, Mooi FR (2014) Global population structure and evolution of bordetella pertussis and their relationship with vaccination. MBio 5:e01074

28. Advani A, Gustafsson L, Ahrén C, Mooi FR, Hallander HO (2011) Appearance of Fim3 and ptxP3-Bordetella pertussis strains, in two regions of Sweden with different vaccination programs. Vaccine 29: 3438-3442

29. van Gent M, Bart MJ, van der Heide HG, Heuvelman KJ, Kallonen T, He Q, Mertsola J, Advani A, Hallander HO, Janssens K, Hermans PW, Mooi FR (2011)SNP-based typing: a useful tool to study bordetella pertussis populations. PLoS One 6:e20340

30. Lam C, Octavia S, Bahrame Z, Sintchenko V, Gilbert GL, Lan R (2012) Selection and emergence of pertussis toxin promoter ptxP3 allele in the evolution of Bordetella pertussis. Infect Genet Evol 12: 492-495

31. Bouchez V, Brun D, Cantinelli T, Dore G, Njamkepo E, Guiso N (2009) First report and detailed characterization of B. Pertussis isolates not expressing pertussis toxin or pertactin. Vaccine 27:6034 6041 
32. Hegerle N, Paris AS, Brun D, Dore G, Njamkepo E, Guillot S, Guiso N (2012) Evolution of French Bordetella pertussis and Bordetella parapertussis isolates: increase of Bordetellae not expressing pertactin. Clin Microbiol Infect 18:E340-E346

33. Barkoff AM, Mertsola J, Guillot S, Guiso N, Berbers G, He Q (2012) Appearance of Bordetella pertussis strains not expressing the vaccine antigen pertactin in Finland. Clin Vaccine Immunol 19:1703-1704

34. Pawloski LC, Queenan AM, Cassiday PK, Lynch AS, Harrison MJ, Shang W, Williams MM, Bowden KE, Burgos-Rivera B, Qin X, Messonnier N, Tondella ML (2013) Prevalence and molecular characterization of pertactin-deficient Bordetella pertussis in the United States. Clin Vaccine Immunol 2:119-125

35. Quinlan T, Musser KA, Currenti SA, Zansky SM, Halse TA (2013)Pertactin-negative variants of Bordetella pertussis in New York State: a retrospective analysis, 2004-2013. Mol Cell Probes 28:138-140

36. Dinu S, Guillot S, Dragomirescu CC, Brun D, Lazăr S, Vancea G, Ionescu BM, Gherman MF, Bjerkestrand AF, Ungureanu V, Guiso N, Damian M (2014) Whooping cough in South-East Romania: a 1-year study. Diagn Microbiol Infect Dis 78:302-306

37. Lam C, Octavia S, Ricafort L, Sintchenko V, Gilbert GL, Wood N, McIntyre P, Marshall H, Guiso N, Keil AD, Lawrence A, Robson J, Hogg G, Lan R (2014) Rapid increase in pertactin-deficient Bordetella pertussis isolates, Australia. Emerg Infect Dis 20:626-633

38. Zeddeman A, van Gent M, Heuvelman CJ, van der Heide HG, Bart MJ, Advani A, Hallander HO, Wirsing von Konig CH, Riffelman M, Storsaeter J, Vestrheim DF, Dalby T, Krogfelt KA, Fry NK, Barkoff AM, Mertsola J, He Q, Mooi F (2014) Investigations into the emergence of pertactin-deficient Bordetella pertussis isolates in six European countries, 1996 to 2012. Euro Surveill 19(33). pii: 20881

39. Tsang RS, Shuel M, Jamieson FB, Drews S, Hoang L, Horsman G, Lefebvre B, Desai S, St-Laurent M (2014)Pertactin-negative Bordetella pertussis strains in Canada: characterization of a dozen isolates based on a survey of 224 samples collected in different parts of the country over the last 20 years. Int J Infect Dis 28 : 65-69

40. van Amersfoorth SC, Schouls LM, van der Heide HG, Advani A, Hallander HO, Bondeson K, von König CH, Riffelmann M, Vahrenholz C, Guiso N, Caro V, Njamkepo E, He Q, Mertsola J, Mooi FR (2005) Analysis of Bordetella pertussis populations in European countries with different vaccination policies. J Clin Microbiol 43:2837-2843

41. Caro V, Njamkepo E, Van Amersfoorth SC, Mooi FR, Advani A, Hallander HO, He Q, Mertsola J, Riffelmann M, Vahrenholz C, Von König CH, Guiso N (2005)Pulsed-field gel electrophoresis analysis of Bordetella pertussis populations in various European countries with different vaccine policies. Microbes Infect 7:976-982

42. Hallander $\mathrm{H}$, Advani A, Riffelmann M, von König $\mathrm{CH}$, Caro V, Guiso N, Mooi FR, Gzyl A, Kaltoft MS, Fry NK, Mertsola J, He Q (2007) Bordetella pertussis strains circulating in Europe in 1999 to 2004 as determined by pulsed-field gel electrophoresis. J Clin Microbiol 45:3257-3262
43. Advani A, Hallander HO, Dalby T, Krogfelt KA, Guiso N, Njamkepo E, von Könnig CH, Riffelmann M, Mooi FR, Sandven P, Lutynska A, Fry NK, Mertsola J, He Q (2013)Pulsed-field gel electrophoresis analysis of Bordetella pertussis isolates circulating in Europe from 1998 to 2009. J Clin Microbiol 51:422-428

44. Mooi FR, Hallander H, Wirsing von König CH, Hoet B, Guiso N (2000) Epidemiological typing of Bordetella pertussis isolates: recommendations for a standard methodology. Eur J Clin Microbiol 19: 174-181

45. van Loo IH, Heuvelman KJ, King AJ, Mooi FR (2002) Multilocus sequence typing of Bordetella pertussis based on surface protein genes. J Clin Microbiol 40:1994-2001

46. Schouls LM, van der Heide HG, Vauterin L, Vauterin P, Mooi FR (2004)Multiple-locus variable-number tandem repeat analysis of Dutch Bordetella pertussis strains reveals rapid genetic changes with clonal expansion during the late 1990s. J Bacteriol 186: $5496-5505$

47. Mooi FR (2010) Bordetella pertussis and vaccination: the persistence of a genetically monomorphic pathogen. Infect Genet Evol 10:36-49

48. Mosiej E, Zawadka M, Krysztopa-Grzybowska K, Polak M, Augustynowicz E, Piekarska K, Lutyńska A (2014) Sequence variation in virulence-related genes of Bordetella pertussis isolates from Poland in the period 1959-2013. Eur J Clin Microbiol Infect Dis [Epub ahead of print]

49. Zawadka M, Mosiej E, Polak M, Krysztopa-Grzybowska K, Moskała B, Rokosz-Chudziak N, Rabczenko D, Augustynowicz E, Lutyńska A (2014) Consistency of Bordetella pertussis vaccine seed strains and potency of whole-cell pertussis vaccine still in use in Poland. Biologicals 42:123-127

50. Borisova O, Kombarova SY, Zakharova NS, van Gent M, Aleshkin VA, Mazurova I, Mooi FR (2007) Antigenic divergence between Bordetella pertussis clinical isolates from Moscow, Russia, and vaccine strains. Clin Vaccine Immunol 14:234-238

51. Octavia S, Maharjan RP, Sintchenko V, Stevenson G, Reeves PR, Gilbert GL, Lan R (2011) Insight into evolution of Bordetella pertussis from comparative genomic analysis: evidence of vaccinedriven selection. Mol Biol Evol 28:707-715

52. Packard ER, Parton R, Coote JG, Fry NK (2004) Sequence variation and conservation in virulence-related genes of Bordetella pertussis isolates from the UK. J Med Microbiol 53:355-365

53. Dakic G, Kallonen T, Elomaa A, Pljesa T, Vignjevic-Krastavcevic M, He Q (2010) Bordetella pertussis vaccine strains and circulating isolates in Serbia. Vaccine 28:1188-1192

54. Lipsitch M, O'Hagan JJ (2007) Patterns of antigenic diversity and the mechanisms that maintain them. J R Soc Interface 4: 787-802

55. Bart MJ, van Gent M, van der Heide HG, Boekhorst J, Hermans P, Parkhill J, Mooi FR (2010) Comparative genomics of prevaccination and modern Bordetella pertussis strains. BMC Genomics 11:627

56. Hegerle N, Guiso N (2014) Bordetella pertussis and pertactindeficient clinical isolates: lessons for pertussis vaccines. Expert Rev Vaccines 13:1135-1146 